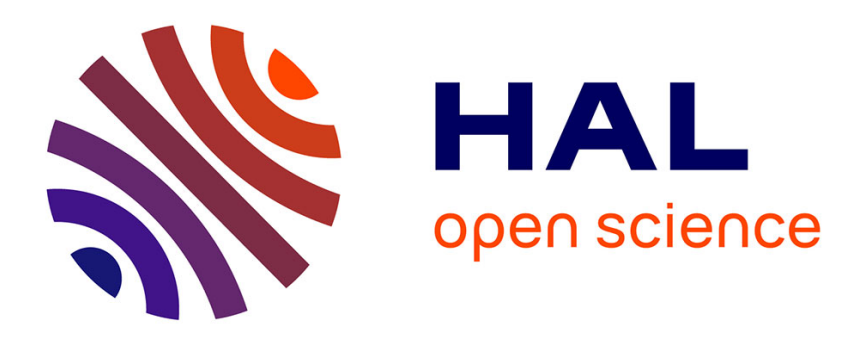

\title{
Interaction between spatial mobility, family and career life-cycle: A French survey \\ Daniel Courgeau
}

\section{To cite this version:}

Daniel Courgeau. Interaction between spatial mobility, family and career life-cycle: A French survey. European Sociological Review, 1985, 1 (2), pp.139-162. 10.1093/oxfordjournals.esr.a036382 . hal02065519

\section{HAL Id: hal-02065519 https://hal.science/hal-02065519}

Submitted on 21 Mar 2019

HAL is a multi-disciplinary open access archive for the deposit and dissemination of scientific research documents, whether they are published or not. The documents may come from teaching and research institutions in France or abroad, or from public or private research centers.
L'archive ouverte pluridisciplinaire HAL, est destinée au dépôt et à la diffusion de documents scientifiques de niveau recherche, publiés ou non, émanant des établissements d'enseignement et de recherche français ou étrangers, des laboratoires publics ou privés. 


\section{Interaction between spatial mobility, family and career life-cycle: $A$ French survey}

\section{DANIEL COURGEAU}

\section{INTRODUCTION}

In the past two decades, scientific research on human spatial mobility has benefited from the greater availability of aggregate data, usually derived from population censuses. Tbe censuses of more and more countries have included questions that elicit information about migration (Morrison, 1983). Research on mobility, therefore, has been broadly concerned with the estimation of migration flows, with the identification of migration propensities by age, sex and other population characteristics and with the explanation of migration by economic and social determinants.

It is beyond dispute that this approach has yielded useful results (Zelinsky, 1983: 30); but it has also raised some new questions. In recent years, the analysis of human spatial mobility has identified some substantive problems not readily solved by aggregate data sets or conventional analytical techniques. Although these problems are both temporal and spatial in nature, here we focus only on the time dimension of migration; the spatial dimension of mobility will not be discussed.

One of the most important regularities observed in human migration is its relationship to age. This relationship seems to recur, with only minor differences, in virtually all developed and developing nations of the world (Rogers, Raquillet and Castro, 1978). It may be attributed to the relationship of age to other personal characteristics and to other aspects of the family life-cycle and work. However, the kind of data obtained from censuses or cross-sectional surveys makes it diffcult to provide evidence for such an interpretation. Furthermore, cross-sectional techniques of analysis cannot tell us whether or not the influence of age may be explained by life-cycle or career characteristics. Let us develop these two points.
First, census data on migration are often obtained (as in France) through a question on place of residence at a specific date (Courgeau, 1980: 195-196).

Such a question gives no information either on the number of migrations or on the duration of each residence. An individual may move more than once within a given period. The most recent move may even be a retum to a former place of residence. In this case, the individual is erroneously registered as a non-migrant. Therefore, it is difficult to link such an approximate timing of migration to other family or carcer cvents.

Secondly, a census will identify certain family or career characteristics without identifying the date at which these characteristics came into effect. For example, an individual may be registered as being married or divorced, but the date of his marriage or divorce is not reported.

It is evident that the combination of these two types of data will give very imprecise or even erroneous results. For example, when we try to connect migration with marriage in France (Deville, 19.79: 6-8) we can provide evidence only for a higher age-specific migration rate for married persons; we are unable to separate migration through marriage from later migrations of married persons. In fact, married persons may have a lower age-specific migration rate than those who are single. As another example, we may know the number of children at census time, but not the date of birth of each child (Long, 1970). In such cases we will be unable to determine if childbirth leads to migration. We can only compare the fertility of migrant and non-migrant women.

We can thus show that cross-sectional data and analytic techniques do not allow us to ascertain the connection between migration on the one hand and 
various characteristics of the family life cycle and work on the other. Clearly, we need more detailed information about the life histories of individuals and techniques of analysis other than the usual migration differential methods.

Retrospective life-history surveys offer a solution to these problems and life-events analyses are well suited to handling such data (Tuma et al., 1979). We will present this approach in detail.

In this paper we will explore both the influence of life events on spatial mobility and the behaviour of birth cohorts in different social, economic, or political contexts. Our field of study is French society, viewed as a structure defined by the interaction of a number of interdependent relational systems (Kimball, 1954); familial, economic, political, and educational.

To study the interrelations of these systems, we consider their expression in time and space through events. Using a retrospective survey schedule, we are able to collect information on events in the occupational, political, educational and family history of interviewees. An event or change of status in one relational system will be followed by an event or change of status in another. For example, a man getting married may change his occupation and his residence. By measuring probabilities of change and investigating the kinds of changes which occur when a new situation arises, we are able to know more about interactions among relational systems.

Since we are primarily interested here in the interaction between migration on the one hand, and family and career life-cycles on the other, we will try to answer eight more specific questions.

(i) How does the occurrence of different events in the family life-cyle affect residential mobility?

(ii) Conversely, how does a migration influence the future course of a family life-cycle?

(iii) How does tenure status influence the duration of residence?

(iv) How does the standard of educational and vocational training influence spatial mobility?

(v) How does the occupational status of an individual influence his residential mobility?

(vi) How do some other socio-political variables (wars, economic crises, etc.) influence spatial mobility?

(vii) How can all the above effects explain the age profiles of migration? (viii) Can we detect some variation in our results from the earlier to the more recent cohorts observed?

Conventional methods of analysing migration differentials are no longer useful. Alternative methodologies include longitudinal demographic analyses (Courgeau, 1977), harmonic analyses (Deiville, 1977), log-linear models (Bishop et al., 1978), and the sociological analysis of individual life histories (Pitrou et al., 1983). We will here adopt both non-parametric and parametric methodologies. These approaches are complementary and will give us satisfactory answers to the above questions.

The non-parametric methods referred to represent a generalization of longitudinal analysis. They are used to study complex interferences between events, including interactions that do not directly generate or impede the phenomenon under observation (Courgeau, 1979). A new impetus was recently. given by the development of the mathematical apparatus needed for the construction of confidence intervals (Aalen et al, 1980; Hoem and Jensen, 1982). Such methods have been used to analyse the reciprocal relations between spatial mobility and fertility.

The parametric methods are based on Kalbfleisch and Prentice (1980) and entail techniques similar to $\log$-linear modelling. The use of these methods in sociology is a recent, but rapidly growing phenomenon (Coleman, 1981; Tuma et al., 1979; Sandefur and Scott, 1981). Here we utilize instantaneous rates of migration as dependent variables, and introduce a relationship between the rates and a variety of observable variables (age, marital status, family size, tenure status, educational and vocational training, job characteristics, etc.). The use of life history data permits us to introduce these characteristics as pre-migration variables, rather than as post-migration characteristics. We shall undertake this parametric analysis step-by-step. We shall begin with family and tenure status as age and duration effect variables, and we shall conclude with economic and political variables. However, once a variable has been introduced into the analysis, it will be retained in the following analyses. In this way we shall be able to see whether or not a previously observed event can be better explained by a new set of variables. In 
particular, we may see whether or not family and economic variables are more relevant to spatial mobility than age.

\section{RESEARCH DESIGN}

The data consist of the retrospective life histories of a random sample of individuals between the ages of 45 and 69 inclusive, all of whom were living in France in 1981. These data were collected from a nation-wide sample of 16,410 households in two different surveys.

One survey, on which we do not actually draw, was intended to ascertain the effects of work on the

$\therefore$ family life of working women. It was directed to young women with children under the age of sixteen. The second survey, which we shall use

- here, dealt with the migration, family and work histories of older individuals. From this survey, we obtained 4,602 completed questionnaires (2,050 for males, 2,552 females) giving a response rate of approximately 89 per cent. ${ }^{1}$ We look here only at individuals who have completed their full-time education and have entered the labour force. We excluded person-place matches where information was missing and where duration of residence was under one year. 22,636 person-place matches remained (including the censored ones). ${ }^{2}$ We consider here all changes in residence within the above duration constraint.

To assess an evolution through time, we separate the observed cohorts into five groups by date of birth; born between 1911 and 1915 , between 1916 and 1920 , between 1921 and 1925 , between 1926 and 1930, and between 1931 and 1935. Sometimes it will be useful to look at larger cohorts, for example, born between 1911 and 1925 , or between 1926 and 1935 . The former cohort would have entered the labor force before World War II, the second one during and after the war.

The retrospective life histories contain information on a number of variables concerning parents' origin, childhood history, marriage and child-bearing history, and detailed job and residence history. To assess the validity of continuous life-histories reported retrospectively, the same questionnaire was used in Belgium. Since this country has a Population Register it is possible to check the data collected against the authority of the Register. The first results show that even if errors in the dating are frequent (Duchène, 1984) the logical sequence of events is usually correct. This finding led us to test the effects of erroneous dating on a parametric analysis, such as the one presented here (Courgeau, 1984). The regularity of the main results confirm a good recall of the logical sequence of events. Thus, memory seems to be reliable where the analysis requires it. However, some more tests will be necessary to confirm these first results.

\section{Methods of Analysis}

Among the great variety of statistical techniques which can be used in the analysis of life-history data, we chose here two which represent complementary approaches.

The first is classical longitudinal analysis, generalized to deal with more complex dependencies between life-history events. There are mainly three ways in which interactions between demographic phenomena can occur. One phenomenon can

(i) prevent the appearance of another phenomenon under consideration (iike death or censoring when studying other phenomens);

(ii) create new behaviour (e.g., marriage creates the possibility of legitimate reproduction);

(iii) neither prevent nor give rise to other phenonema being studied.

The first two kinds of interaction have long been studied and methods of analysis have been developed. The third one is more complex and leads to a dual analysis of two or more phenomena studied jointly.

We use non-parametric methods bere to analyse the reciprocal relations between spatial mobility and fertility. We will develop, in this paper, an analysis of the longer-term effects of the level of each of these two status dimensions (number of spatial moves experienced and childbearing parity) on the other. We leave aside the short term after-effects of the occurrence of any event. (A more comprehensive approach is developed in appendix 1). We have thus to answer the following two questions:

(i) What will be the effects of $n$ births after marriage on migration? 
(ii) What will be the effects of $l$ moves after marriage on childbearing propensity?

In order to address the questions, let us observe married couples according to their age at the time of marriage, and let us consider here those who have $n$ children ( $n$ may equal zero) during a marriage of $i$ years. Let their number be $S_{i}^{*}$. During the time interval $(i, i+1), N_{i}^{n}$ women give birth to their $n^{\text {th }}$ child, while $N_{i}^{n+1}$ women give birth to their $(n+1)^{\text {th }}$ child. We suppose here that every move undertaken during the $n^{\text {th }}$ birth year is to be related to the population of women with $n$ children. During the same interval some couples may be censored, as the survey occurred during time $\left(O_{7}^{7}\right)$. We suppose here that they remain in the risk set during 0.4 of a year, because the survey took place during the spring of 1981 (Riandey, 1984). Finally, we propose the hypothesis that the behaviour of those married couples is dependent on the duration between marriage and migration and on the birth rank of the child, but not on the duration between previous births and the migration considered.

Thus, if we register $E^{n}$ moves occurring during the same time interval for the couples with $n$ children, we can write the following mobility rate ${ }^{3}$ $\left(e_{i}^{n}\right)$ :

$$
e_{i}^{n}=\frac{E_{i}^{n}}{S_{i}^{n}+N \eta-N \eta^{+1}-0.60 \eta}
$$

The comparison of rates with the same duration $i$, but for different numbers of children $n$, provides an answer to the first question we posed above. We can use the following test to see if the observed differences between $n$ and $(n+1)$ children are significant or not (Hoem, 1982). If we expect a priori that $e_{i}^{n} \leqslant e_{i}^{n+l}$ for some durations $i$, ( $m$ ), and want to test the hypothesis $e_{i}^{n}=e_{i}^{n^{+1}}$ against the alternative $e_{i}^{n}<e_{i}^{n^{+1}}$ for at least some durations $i$, we can form the following test statistic:

$$
\begin{aligned}
& e_{i}^{n+1}-e_{i}^{n}
\end{aligned}
$$

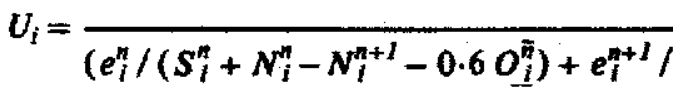

$$
\begin{aligned}
& \left.\left(S_{l}^{n+1}+N_{i}^{n+1}-N_{i}^{n+2}-0.6 O_{i}^{n+1}\right)\right)^{\frac{1}{2}} \\
& \text { and } U=\frac{1}{\sqrt{m}} \sum_{i} U_{i}
\end{aligned}
$$

It could be shown that $U_{i}$ and $U$ are asymptotically normal $(0,1)$ and a test of this normality can be undertaken.

To answer the second question, let us consider the couples with $l$ previous moves (where $l$ may equal zero) at a duration of marriage of $i$ years $\left(P_{i}^{l}\right)$. During the time interval $(i, i+l) M_{i}^{l}$ couples undertake their the move, while $M_{i}^{+t}$ undertake their $(l+1)^{\text {th }}$ one. We suppose here that every child born during the year of the ${ }^{k}$ move is to be related to the population having $(l-1)$ prior moves, so that such a measure will mainly take into account later births. There are also $O$ i couples censored during the same interval. If we register $F$ / children born during this interval, for couples with $l$ moves, then - :we can propose the following fertility rate $(j)$ :

$$
f_{i}^{l}=\frac{F_{i}^{l}}{P_{l}^{l}+M_{i}^{l}-M_{i}^{l+1}-0.6 O_{i}^{l}}
$$

The comparison of such rates with the same duration $i$, but for different numbers of moves $l$, provides an answer to the second question.

When adding the successive values of $e_{f}^{n}$ (resp. $f i)$, got $i=I, \ldots d$, we obtain a cumulative spatial mobility index until time $d$ for the fictitious population of women of parity $n$ (resp. the cumulative marriage fertility of women with $l$ moves). However, as the risk set may be zero or near zero for short durations and values of $n$ or $l$ greater than zero, we hypothesize that, until the risk set contains less than 50 individuals, the cumulative mobility index (resp. the cumulative marriage fertility) of couples with $n$ children (resp. $l$ moves) is the same as the cumulative mobility index of couples with ( $n-I)$ children (resp. $l-1$ moves).

These results lead to the concept of local dependence (Aalen et al., 1980) on the introduction of a dynamic property developing over time and $t$. having a specific direction. Such a concept formalizes the intuitive notion that a stochastic process may influence the local development of -: another process at some time $t$. Hence, local dependence is a dynamic property developing over time. A phenomenon may be locally dependent on another, yet this second phenomenon may be locally independent of the first. Such an analysis leads to results allowing stronger inferences of causality than would a simple correlation analysis. 
This method is useful for ascertaining the interaction of a limited number of demographic events. To obtain valuable results with a large set of events, an increasingly larger sample size is required. Since our sample is limited, a parametric model will be more useful for assessing the effect of many variables.

The parametric model (developed in more detail in appendix 2) uses a formulation of the instantaneous migration rate as a variable which is, in turn, dependent on a number of other variables. Such an instantaneous migration rate, subject to the condition that no change of residence occurs before time $t$, is supposed to be related to the observable variables in a generalized Gompertz model:

$$
\mu\left(t ; X_{b}, \theta\right)=\exp \left(\theta X_{i}+\theta_{O} t\right)
$$

in which $X_{i}$ is the vector of observed variables and $\theta$ is a vector of estimated regression parameters. Previous migration analysis has already shown a very good fit of regression models to Gompertz' duration of residence effect (Ginsberg, 1979). Such models give results almost identical to a mover/stayer model, previously fitted to French data (Courgeau, 1980). This estimate can be used to test many hypotheses on the values of the $\theta$ coefficients (Kalbfleisch and Prentice, 1980).

\section{Measures of Variables}

Table $I$ contains the measures of the 37 variables which are utilized in the parametric analysis. With the exception of duration of stay, all variables are measured at the beginning of the person-place match. We first introduce age-group variables with duration of stay, then family life-cycle variables, tenure status variables, career variables and finally some more general ones like war periods or - economic crisis periods.

\section{RESULTS}

Let us first present the results from the more simple model, introducing a constant instantaneous rate for all observed periods. Such an exponential model may be written: $\mu(t)=\exp (\theta)$.

The evolution of male and female cohortst at this constant rate is given in Table 2 and Figure 1. We can observe that the rates computed for

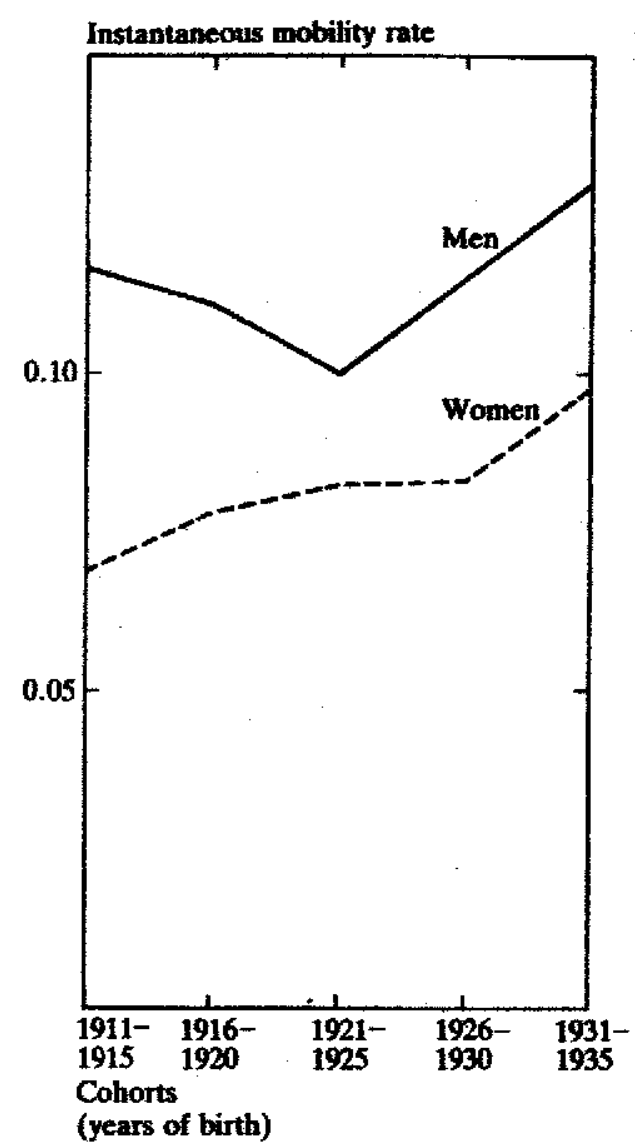

Figure I Instantaneous Mobility Rates for the Different Cohorts

women are always lower than those for men. This may be linked to the fact that some political moves (e.g. National Service) apply only to men. However, we observe an increasing mobility rate for younger female cohorts. The mobility rate applied from the age of 15 to the age of 50 give 2.41 moves for the cohort born between 1911 and 1915 against 3.40 moves for the cohort born between 1930 and 1935 . For males, we observe an initial decrease in the mobility rate for the cohorts most affected by World War 11 (born 1916-1925) and a subsequent increase. The decrease is to be linked to the fact that, between 1940 and 1944, few men did their military service (mainly short-term periods). We observe 4.07 moves for the male cohort born between 1911 and 1915 , and 4.36 moves for males born between 1931 and 1935. 
INTERACTION BETWEEN SPATIAL MOBILITY, FAMILY AND CAREER LIFE-CYCLE

TABLE 1 Measures of Varlables

\begin{tabular}{|c|c|}
\hline Variables & Indicator \\
\hline \multicolumn{2}{|l|}{$\begin{array}{l}\text { Age group (less than } 20 \text { years, } 20-24,25-29,30-34 \text {, } \\
35,39,40-44,45-49 \text { ) }\end{array}$} \\
\hline Marital status & $\begin{array}{l}0 \text { single } \\
1 \text { married }\end{array}$ \\
\hline Divorced & $\begin{array}{l}0 \text { not divorced } \\
1 \text { divorced }\end{array}$ \\
\hline Widowed & $\begin{array}{l}0 \text { not widowed } \\
1 \text { widowed }\end{array}$ \\
\hline Departure of the first child & $\begin{array}{l}0 \text { no child out } \\
1 \text { at least one child out }\end{array}$ \\
\hline Number of children & number born at the beginning of the observation \\
\hline Number of sibs & number of sibs \\
\hline Elder & $\begin{array}{l}0 \text { if no } \\
1 \text { if elder }\end{array}$ \\
\hline Number of parents' residences & number up to 14 years old \\
\hline Lodged by parents & $\begin{array}{l}0 \text { if not } \\
\text { if lodged by parents }\end{array}$ \\
\hline Homeowner & $\begin{array}{l}0 \text { if not } \\
1 \text { if owner }\end{array}$ \\
\hline Lodged by employer & $\begin{array}{l}0 \text { if not } \\
1 \text { if lodged by exployer }\end{array}$ \\
\hline Working status & $\begin{array}{l}0 \text { if not employed at the beginning of the observation } \\
1 \text { if employed }\end{array}$ \\
\hline Public sector & $\begin{array}{l}0 \text { if not employed in public sector } \\
1 \text { if employed in public sector }\end{array}$ \\
\hline Education & $\begin{array}{l}\text { from } 0 \text { (no diploms) to } 8 \text { (training from colleges of university } \\
\text { level) }\end{array}$ \\
\hline Vocational training & from $O$ (no diplona) to B (graduate engineer) \\
\hline Self-employment & $\begin{array}{l}0 \text { if not } \\
1 \text { if self-employed }\end{array}$ \\
\hline $\begin{array}{l}\text { Socio-professional group (farmers, farm labourers, exe } \\
\text { in industry and commerce, managerial stafi, essistant } \\
\text { managers, other staff employees, manual workers) }\end{array}$ & $\begin{array}{l}0 \text { if not in this group } \\
l \text { if in this group }\end{array}$ \\
\hline 1931 crisis & $\begin{array}{l}0 \text { if the period did not begin during the years 1931-1935 } \\
1 \text { if the period begun during the yeare 1931-1935 }\end{array}$ \\
\hline 1974 crisis & $\begin{array}{l}0 \text { if the period did not begin during the years } 1974-1981 \\
1 \text { if the period begun during the years 1974-1981 }\end{array}$ \\
\hline War period & $\begin{array}{l}0 \text { if the period did not begin during the years 1939-1944 } \\
1 \text { if the period begun during the years } 1939-1944\end{array}$ \\
\hline National Service & $\left\{\begin{array}{l}0 \text { if not in National Service } \\
1 \text { if in National Service }\end{array}\right.$ \\
\hline Naturalized & $\begin{array}{l}0 \text { if not naturalized } \\
1 \text { if naturalized }\end{array}$ \\
\hline Foreigner & $\begin{array}{l}0 \text { if not a foreigner } \\
1 \text { if a foreigner }\end{array}$ \\
\hline Duration of residence & number of years lived in the current residence \\
\hline
\end{tabular}


TAalx 2 Mobility Rates for Duration of Residence Beginning Before the Age of 45

\begin{tabular}{|c|c|c|c|c|}
\hline \multirow[b]{2}{*}{ Cohort } & \multicolumn{2}{|c|}{ MEN } & \multicolumn{2}{|c|}{ WOMEN } \\
\hline & Mobility rate & Number of cases & Mobilfity rate & Number of cases \\
\hline Borm 1911-1915 & 0.116 & 1,944 & 0.069 & 2,038 \\
\hline Born $1916-1920$ & 0.110 & 1,433 & 0.077 & 1,638 \\
\hline Born $1921-1925$ & 0.099 & 2,253 & 0.082 & 2,218 \\
\hline Born 1926-1930 & 0.114 & 2,224 & 0.083 & 1,926 \\
\hline Born $1931-1935$ & 0.125 & 2,454 & 0.097 & 2,034 \\
\hline
\end{tabular}

We will now report the estimates of the $\theta$ parameters. For dummy variables, we will also give the antilog of the parameters $(\exp (\theta))$ which indicates the multiplier of the rate when the variable is unity. We also present likelihood ratio tests (used to determine whether or not the parameter differs significantly from zero), a test of comparison with the previous exponential model, and $a$ test of comparison with the last presented model.

\section{The Effects of Age and Duration of Stay}

Since many previous studies have demonstrated an important effect of age on duration of stay, we will see first if such an effect remains valid in the framework of a longitudinal approach.

Table 3 contains the results of a model in which age-coded as a set of dummy variables-and duration of stay are the independent variables. The comparison group consists of person-place matches where the persons involved are over the age of 45 . This model gives a substantially better likelihood ratio test than the previous one (same rates for all observed periods). For men, conventional period-analysis results hold true: individuals aged $20-24$ have the maximum rate (from 3.6 to 6.0 times higher than for the - comparison group, aged 45 years or more). For women, we observe lower rates at younger ages; but we no longer observe maximum rates for the age group 20-24. Results for men and for women become more similar at later ages. A shift of three to five years is observed, reflecting differences in age at time of marriage.

The duration effect is always highly significant, but not to the same degree for both men and women. It corresponds to a decrease of the mobility rate over time. After a 10 year duration, the mobility rate will be reduced by half for men and by a third for women.

However, no clear pattern emerges from the results across the different cohorts. Only one significant decrease appears. It occurs in the rate of the 20-24 age-group among male cohorts born between 1911 and 1925. Complex interactions are involved between different age-groups and certain economic and political crises in this evolutionary pattern. The following analysis attempts to identify such interactions.

\section{The Effects of Family Life-Cycle and Tenure}

Status

When we introduce family and tenure status variables, some new results appear. Table 4 contains the results of such an analysis. The tests indicate that this model represents a substantial new improvement over the previous one.

First, from the three variables giving information on family history-number of siblings, birth order and parents' mobility during childhood-only the last one gives a significant effect. The effect is positive, indicating an "inheritable' propensity to move: the children of parents who undertook many moves will themselves be more mobile than the average population. This result remains constant even when more variables are introduced.

Marital status also plays an important role in migration. The migration rate of individuals is reduced by a third after marriage. However, some differences appear from one cohort to another. The first cohorts show little effect of marriage on mobility. Even for men born between 1911 and 1915, the effect of marriage is insignificant when the next economic and political variables are 
INTERACTION BETWEEN SPATIAL MOBILITY, FAMILY AND CAREER LIFE-CYCLE

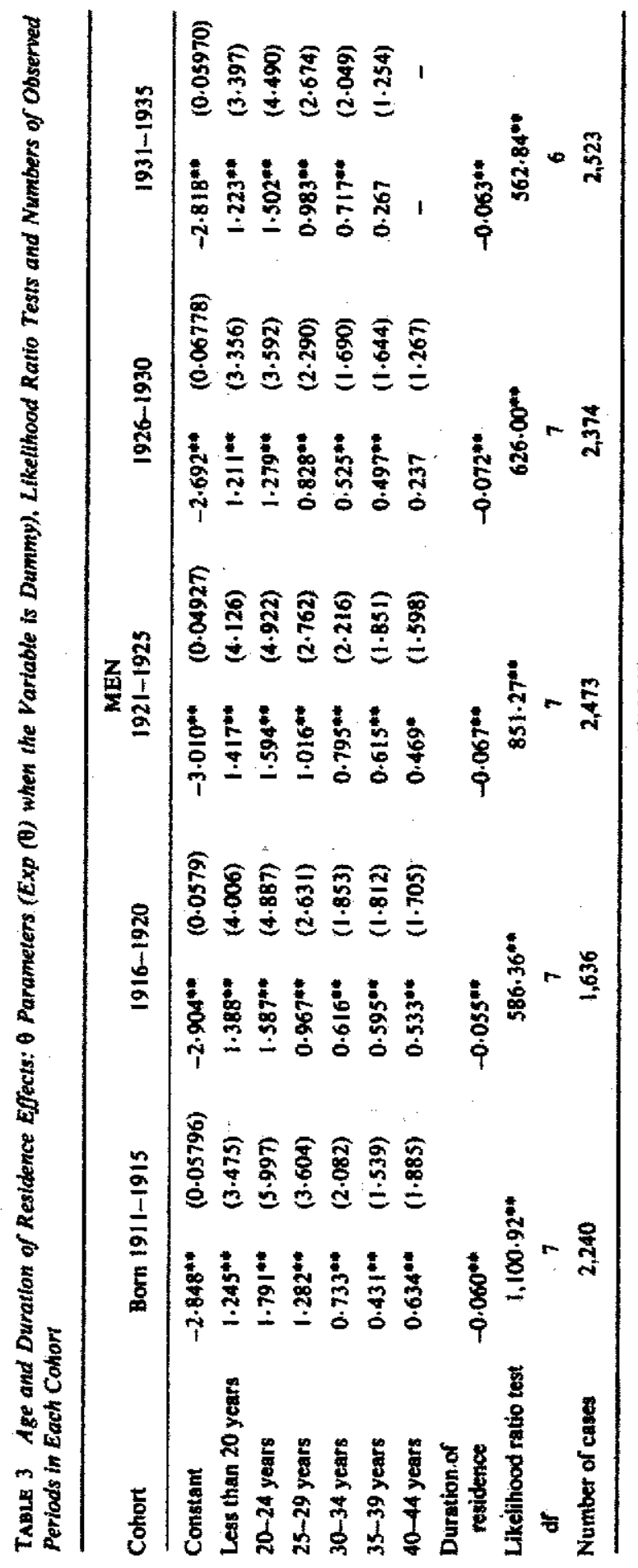

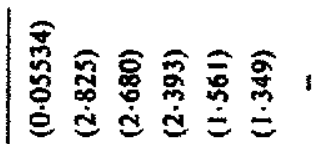

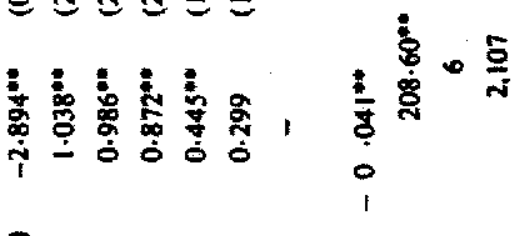

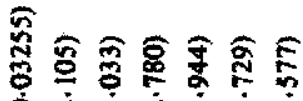

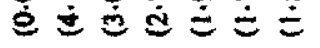

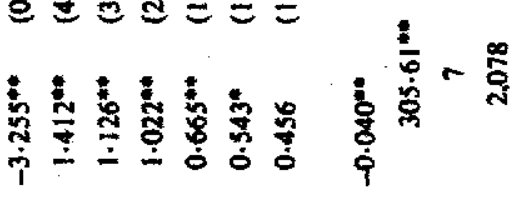

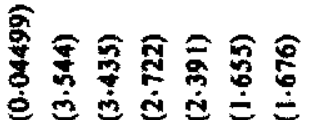

变

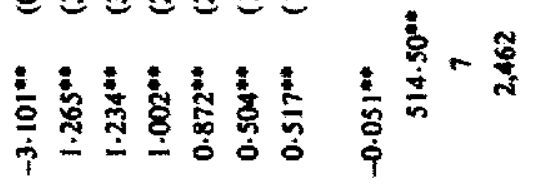

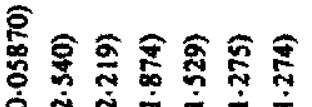

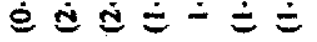

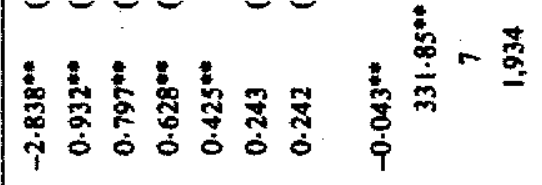

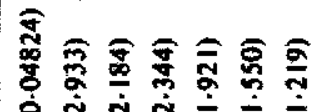

这灾空踣

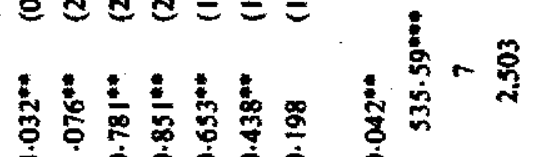

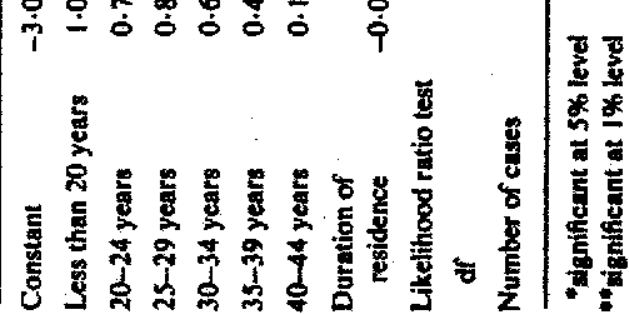




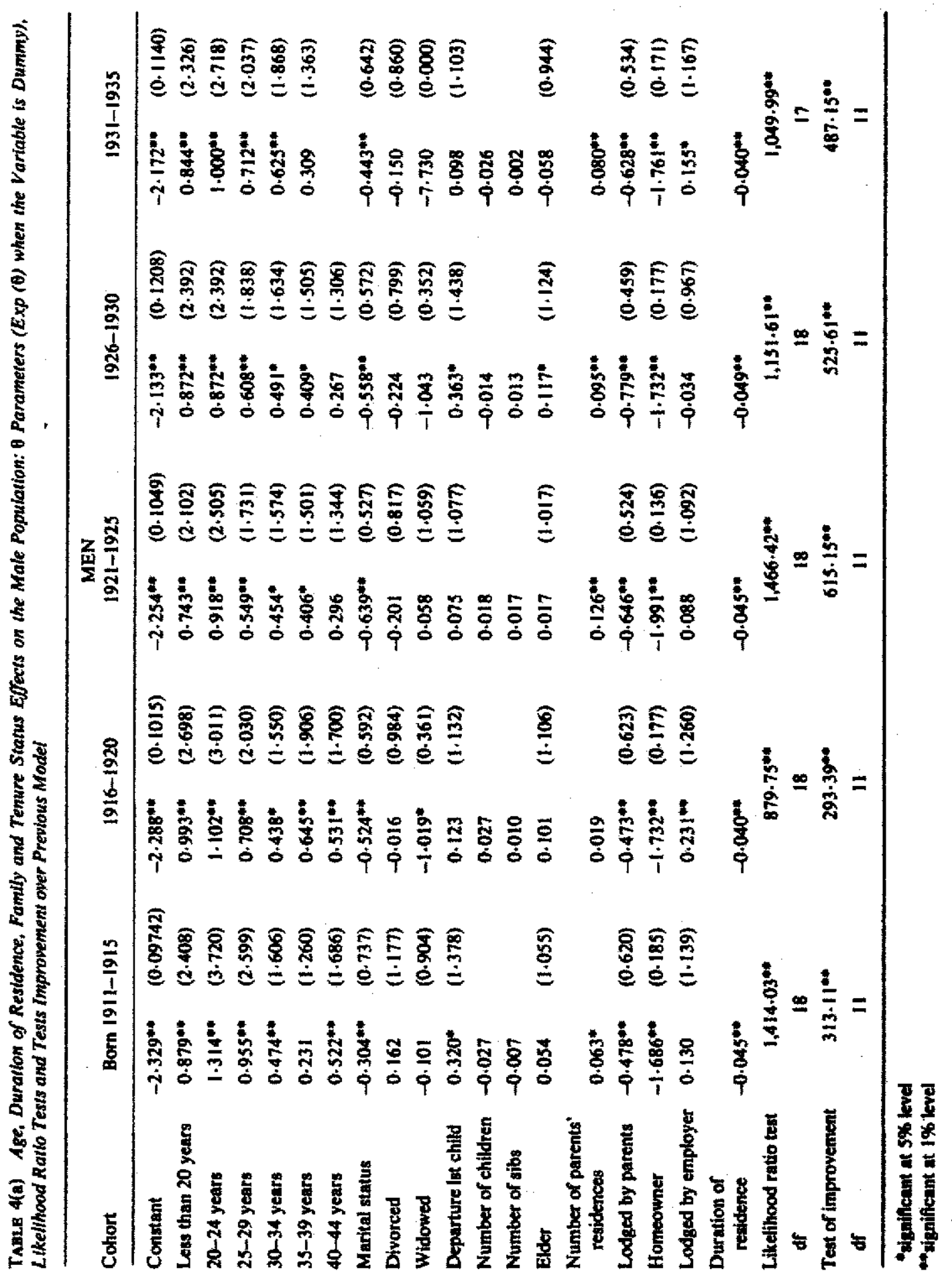




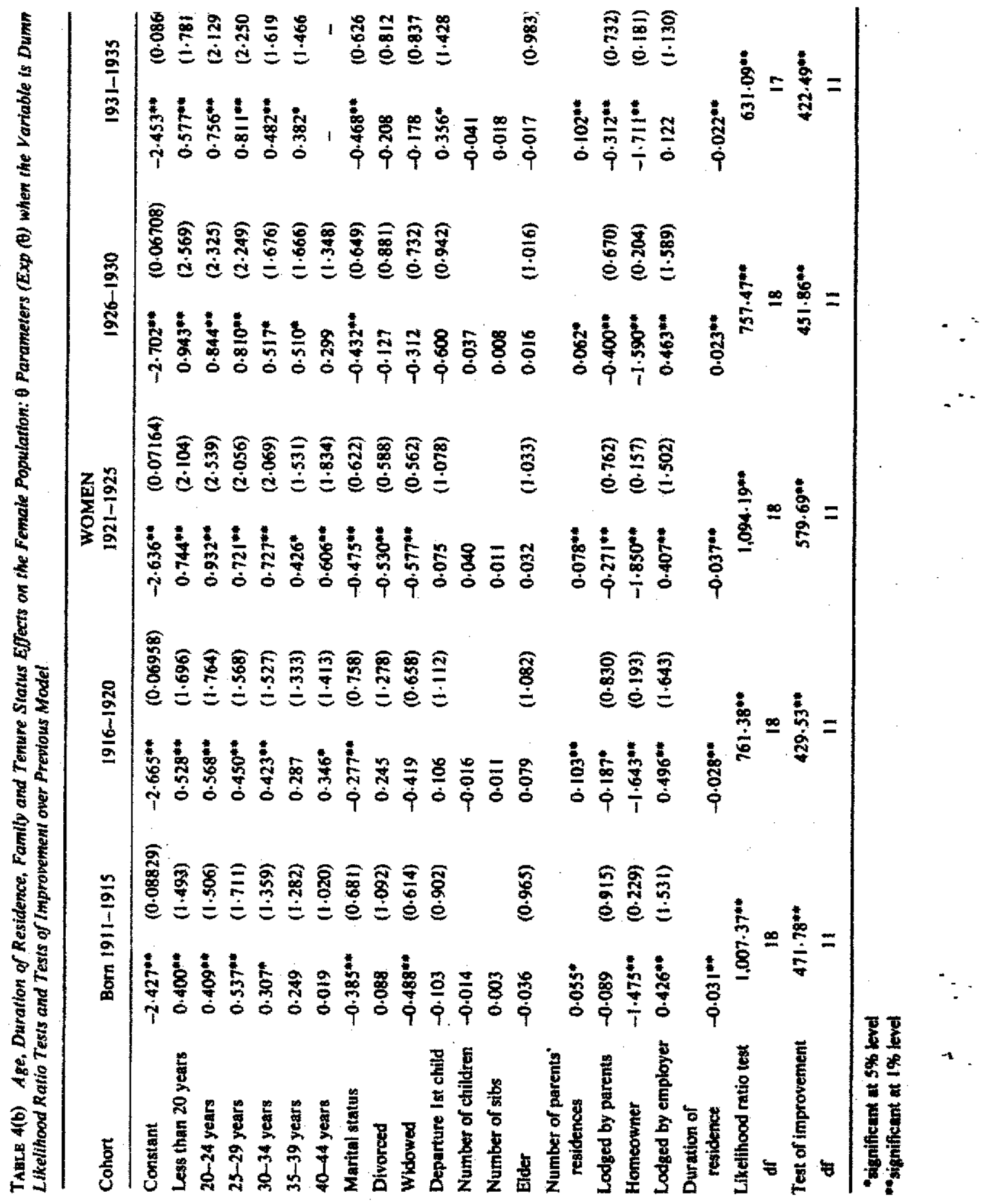


introduced. Divorce and widowhood (of which we find enough cases only among the three first cohorts) have significant effects, mainly for women. Widowhood reduces the migration rate among women by a third. For divorce, a significant reduction occurs only for the femaje cohort born between 1920 and 1930. Either effect, or an inverse effect occurs for the earlier cohorts.

The next family events are the birth of children (measured by their number at the beginning of the period) and the departure of the first child. Only the departure of the first child shows a significant effect: it will induce an increase in the mobility rate. Once the process of the departure of children

- 'starts, new migration to more appropriate housing is observed. Surprisingly, the number of children born has no obvious effect on spatial mobility.

- Let us here observe how different approaches may be developed. In this parametric analysis, the variables having an effect on the migration rate are measured at the beginning of the person-place match. Thus, an individual who has not moved after marriage but who has since had one or two children will be considered as having no children at the beginning of the match. It seems necessary then, to take another point of view, to emphasize the effects of family size immediately prior to migration. It may also be useful to study the interdependence between mobility and fertility. A move may be undertaken before the birth of any children, in order to have a house of adequate size and thus to avoid multiple moves.

Non-parametric methods of analysis seem adequate for such an analysis. We have divided the observed population into 2 larger cohorts (born between 1911 and 1925 and between 1926 and 1935), and into 2 categories corresponding to age at marriage (married before 23 years old/married between 23 and 30 years old. In order to have comparable results based on the age of the wife at marriage, we will define the first cohort to consist of women born between 1911 and 1925 married to . men who were born between 1911 and 1935 and of the surveyed married men whose wives were born between 1911 and 1925. The second cohort will consist of women born between 1926 and 1935 married to men born between 1911 and 1935 and of the married men whose wives were born between 1926 and 1935 . With these conditions the results are perfectly comparable.
The results are given in Table 5 , as cumulative mobility rates (cf. fertility rates) for different family sizes (cf. numbers of migrations undertaken). For the first years after marriage, when the risk set is kess than 50 individuals, we suppose the behaviour of such a subpopulation to be the same as that of the subpopulation with one child less (cf. one migration less).

The behaviour of the two cohorts is quite similar. The main differences appear between women married before and after the age of 22 . For those married younger, there is a clear effect of family size on the cumulative number of moves: the higher the size, the more mobile the subpopulation will be.5 This result shows migrations following child birth (or being undertaken the same year, just as we related a move during the year of a $t^{h}$ birth to the population already having $l$ children) to be more numerous than migrations where no childbirth has occurred. This result may be explained by the need to adjust the size of dwelling to the size of the family. This effect is very clear for the low birth ranks, but it is less perceptible for the higher ones. We may link this result to a difference in the socio-economic composition of couples with two children or less and couples with more than two children. We know that the more fertile subpopulations are farmers, farm labourers and factory workers (Calot and Henry, 1972) and we will later observe that those subpopulations are the less mobile ones. It may be useful, then, to split the observed population into occupational subgroups; but the subpopulations will be too small to permit clear conclusions.

On the other hand, still considering women married before the age of 22, the cumulative fertility of couples-according to their number of previous moves-also indicates that some moves are undertaken to provide for forthcoming births. Since we here related a birth during the year of the th move to the population having $(-1)$ prior moves, such a measure takes into account only the births occurring after the year of migration. Thus, such an analysis permits us to say that, if young married women undertake a migration after child-birth to adjust their dwelling size to their family size, some migrations may also be undertaken to permit a forthcoming increase of family size.

For women married over the age of 22 , the effect 
INTERACTION BETWEEN SPATIAL MOBILITY, FAMILY AND CAREER LIFE-CYCLE

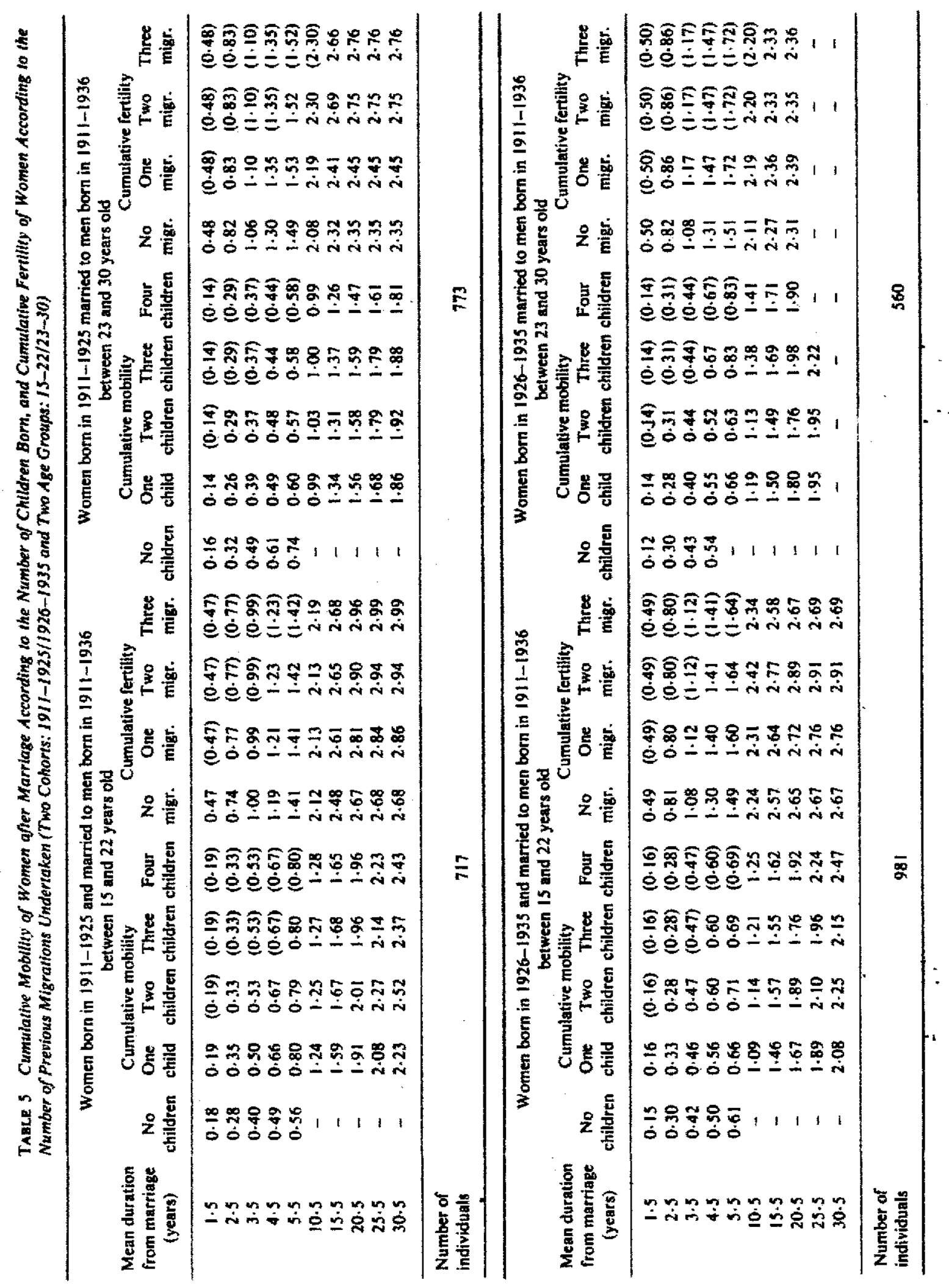


of family size on the number of moves has entirely disappeared. No differences can be detected between women without children and women with one, two, three or more. These women seem more likely to have a sufficiently large home to accommodate their ultimate family size. The number of children born, therefore, does not affect mobility. It initially seems that these women are mainly wives of executives, or management staff in industry and commerce and that they have a high level of vocational training (Calot and Henry, 1972). But some interesting results emerge (quite clearly for the elder cohort, less surely for the younger one): the cumulative fertility of these women-according to the number of previous moves-indicates that some moves are undertaken in anticipation of a birth. Thus, in these cases, we

- find a local dependence of fertility on spatial mobility: if no further moves are undertaken in or after the year of a birth (these women have the same mobility whatever number of their previous births), it appears that some moves may have been undertaken in anticipation of future births in the household. Thus, a non-parametric analysis has been useful here to explain the interaction between fertility and migration.

Let us now return to the parametric analysis, introducing tenancy status variables which are linked simultaneously to the family life-cyle and to the economic life-cycle. The comparison group here consists of the tenured individuals.

In the first stage, an individual may be living with his parents. In the population studied, one fourth of the periods observed fall into this category. It would seem that people in this situation are less likely to migrate than people in the comparison group. However, there is a clear difference between older and younger cohorts in this regard. For the older cohorts, the correlation is not significant for women. It becomes significant at the level of 1 per cent only from the third cohort on. For men, the result seems to be significant as of the first cohort but as we shall see when the economic variables are introduced, it will also disappear for the older cohorts. This last observation is linked to the fact that farmers live with their parents on family farms and their tenancy status changes when the father dies or retires. For more recent cohorts, such situations are less common.
Individuals lodged by their employer will, for their part, have a higher mobility rate than tenants because they have a greater need to adapt their residence to the needs of the employer. Such adaptation occurs mainly among women and become less frequent among the most recent cohorts.

The most important change, however, occurs when an individual becomes a home-owner. The mobility of home-owners decreased sevenfold compared to the mobility of a tenured individual. It increases for the three first cohorts and shows decreases for the more recent ones. Such changes are linked to the evolution of the French housing market. Until the 1950s, subsidies for the purchase of a house were rare. For people in the cohorts born 1911-1926, the status of home-owner would have been attained only after numerous years of saving. Once this status was attained, homeowners were compelled to remain in the same house by housing shortage. Such was the situation until the 1950s. The creation of state loans and an increase in residential construction created many new opportunities for more recent cohorts to own their homes. In addition, an increase in the availability of personal loans made it possible for young owners to keep their previous residence as an investment.

Finally, we can observe that the effects of both the duration of residence and age of the subject are significantly reduced when family and tenancy variables are introduced. We will develop this point in greater detail at the end of this paper.

\section{The Effect of Occupational Status and Political Conditions}

Table 6 shows the results of an analysis where economic and political variables are introduced. Again, the tests indicate a substantial new improvement over conventional analysis. Let us study these results.

First the level of educational and vocational training, introduced here in a scale, seems to be linked to spatial mobility only for the two last cohorts. For men, the two levels have an independent and significant effect. An individual with a higher level academic degree will be more and more open to employment in an increasingly larger field. The same is true for the men with vocational training. For women it seems that 


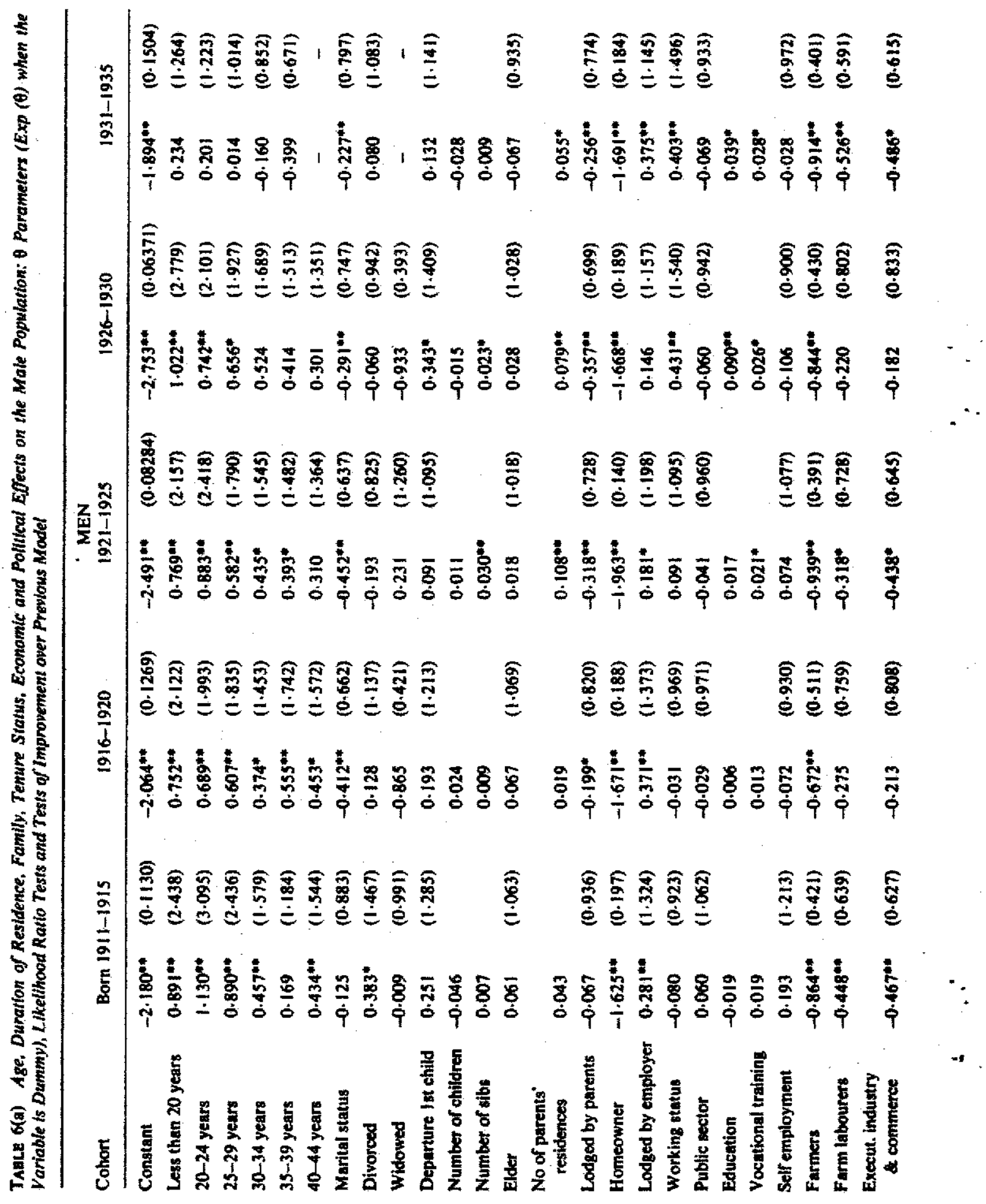




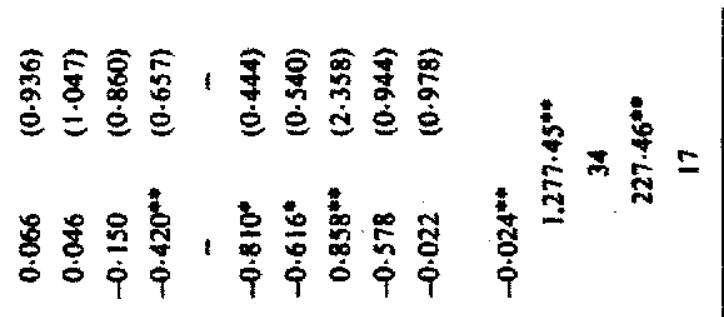

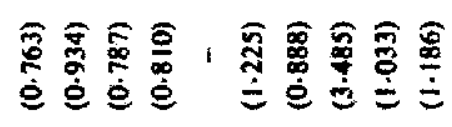

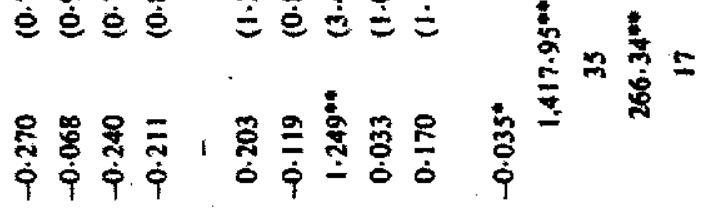

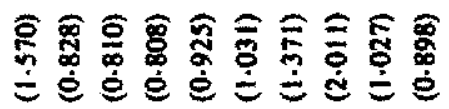

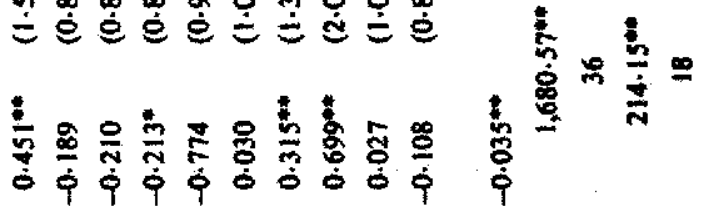

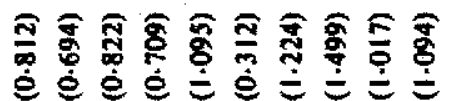

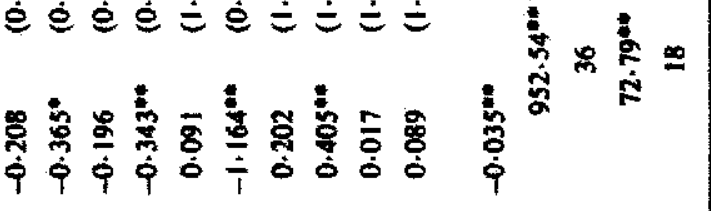

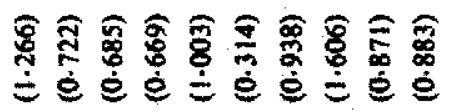

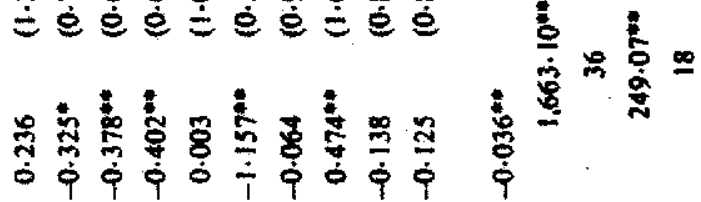

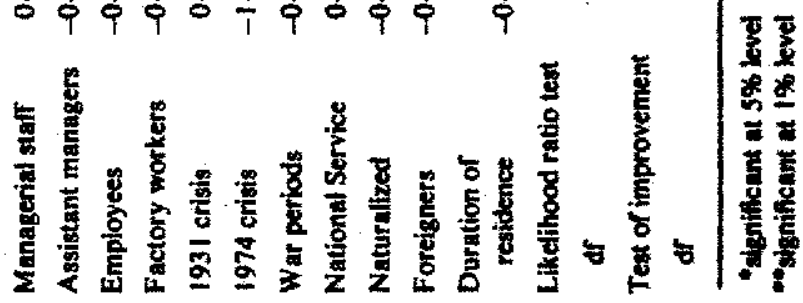




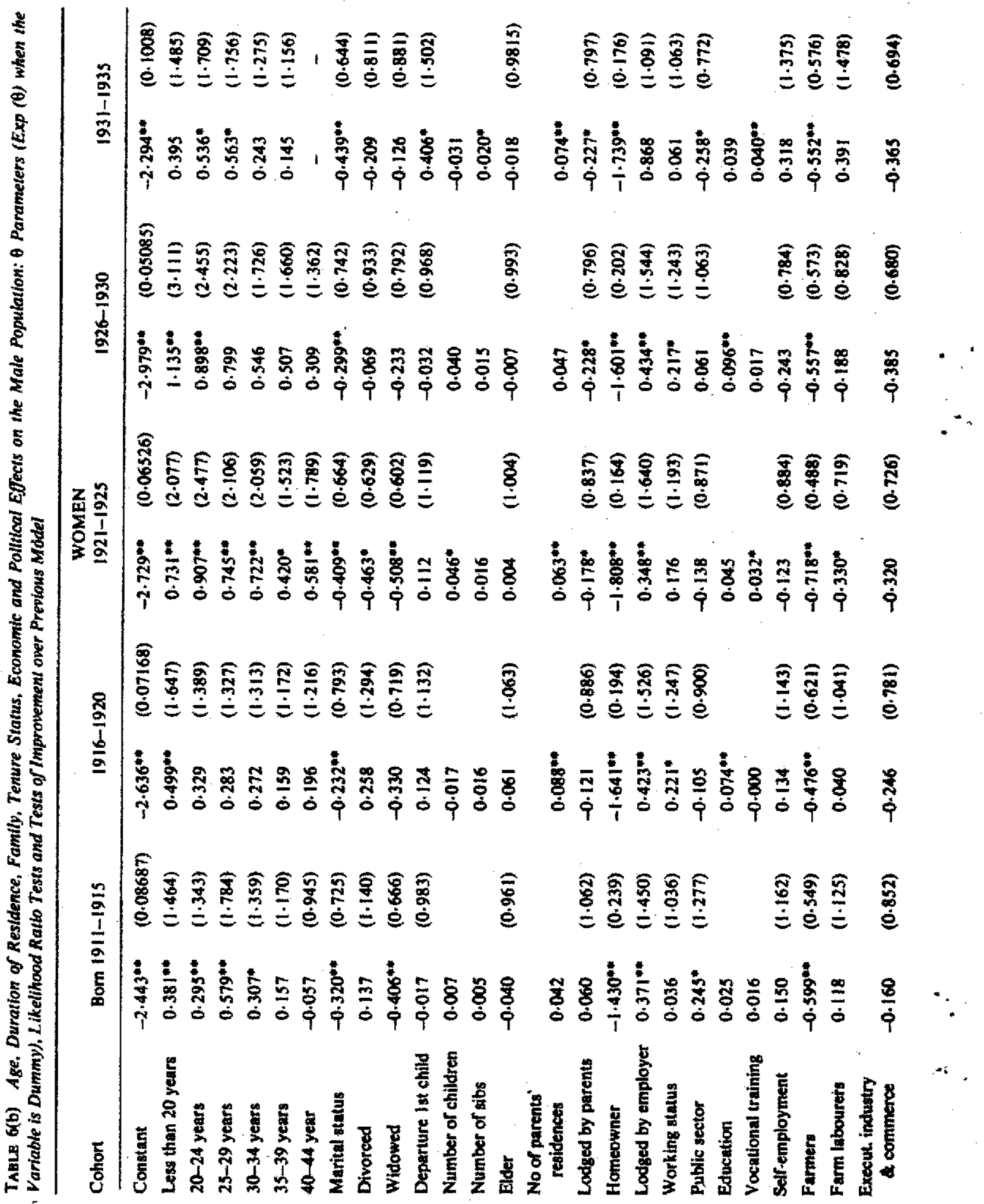




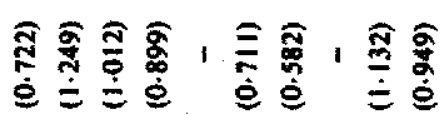

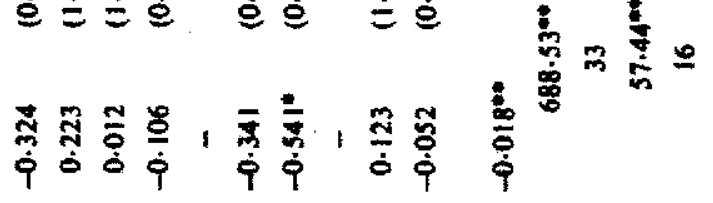

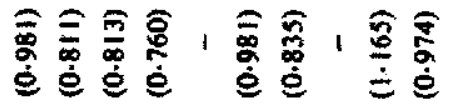

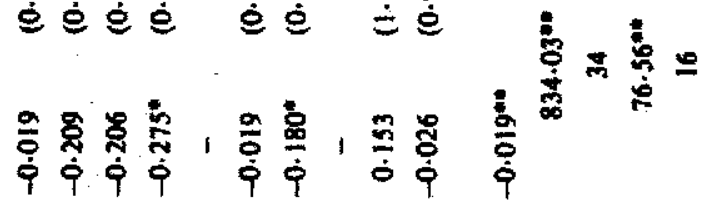

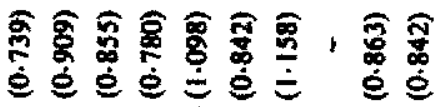

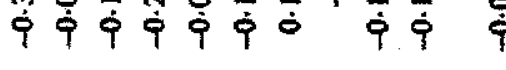

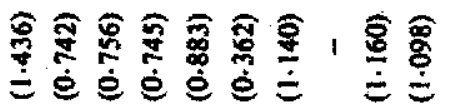

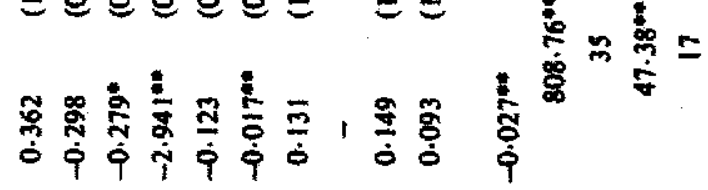

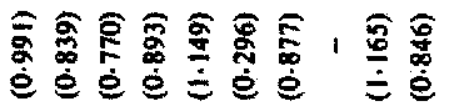

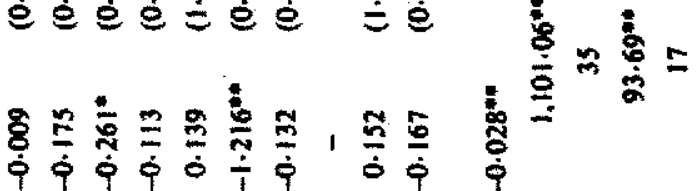

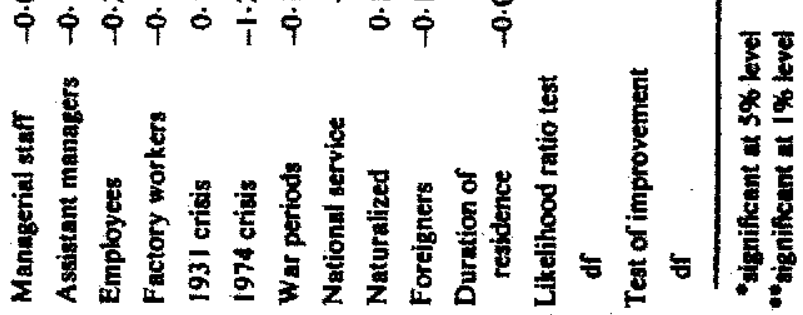


diplomas and vocational training play interchangeable roles in influencing their mobility rates. It is interesting to observe that no influence on mobility can be derived from these variables for the earlier cohorts.

Now let us observe the effect of different employment statuses; i.e. employed or unemployed at the beginning of the observed period, employed in or out of the public sector, self-employed or not self-employed.

For older cohorts, employment or unemployment at the beginning of residence has no effect on mobility. For more recent cohorts (males bom between 1925 and 1930 , and females in eartier cohorts), employment leads to increased mobility. This result may be linked to the acceptance of work far from a former residence, followed by a return to the previous workplace.

For men working in the public sector, no effect is observed. For women in the public sector, effect on mobility has only a $S$ per cent significance level and seems, moreover, difficult to explain: it moves in an opposite direction from the first cohort to the last one. The case of self-employment produces no significant effects.

More important is the effect of occupational status on mobility. We introduce here seven occupational statuses: farmers, farm labourers, executives in industry and commerce, managerial staff, assistant managers, other staff employees and manual workers. The comparison group consists of categories which are quite heterogeneous but have too few members to be considered separately (attendants, military personnel, artists, clerical personnel, housekeeping staff, servants and the non-working population). In order of least to most mobility we have farmers followed by farm labourers, and industrial and commercial executives. Next we have manual workers, other staff employees, and assistant managers. For the last group an evolution through the different cohorts leads to the same mobility rate observed for the control group. The most mobile groups will be managerial staff; but the mobility of this group also decreases to the level of the control group for the last cohorts observed. Such results are more significant for men than for women. However, the classification scheme remains similar for both sexes, although farm labourers and managerial staff include very few women.
Finally, let us see how some important economic and political events affect mobility rates. First, National Service creates clearly differentiated periods in the life of males. Even though the duration of service has fuctuated (from 1 year to 3 years) National Service always leads to an increase in the migration rate.

Secondly, residences that began during the World War II period lead to very different results for older and younger cohorts. For the oldest (born between 1915 and 1925), the war increased their mobility rate. Those men and women who had already begun work before the war were greatly affected by its outbreak and were caught up in some new mobility processes (e.g. war exodus, periods of imprisonment, etc.). Even when interviewers were instructed not to solicit details ". concerning this disturbed period, the disturbance is clearly evident in the number of residences of short duration. The other cohorts that began to work during the war period exhibited opposite behaviour patterns. For those young men and women, the residence periods are longer. When these people found a place to work they tended to stay there, since it was difficult to find better work elsewhere.

Thirdly, two periods of economic crisis (19311935 , and 1974 and after) lead to different behaviour. The first crisis period did not significantly alter the mobility of French population. On the other hand, the second economic crisis significantly reduced the mobility of both young and old. A similar effect has been observed in other countries during periods of economic crisis (Eldridge, 1964).

Lastly, being either a foreigner or a naturalized citizen plays no effect on the mobility rate. Previous international mobility does not lead to a more residentially mobile population.

\section{Reduction of Age and Duration Effects}

The introduction of family variables has led us to notice a reduction of the effects of age. We will here present in more detail how this reduction occurs.

Figures 2 and 3 permit the comparison of this evolution between the first and last cohorts when different kinds of variables are introduced. First, we can see that, even if family variables play a part in the reduction of the rates for the age-group of 15-24 in the last cohort, they had no effect on the age rates for the male cohort born between 1911 

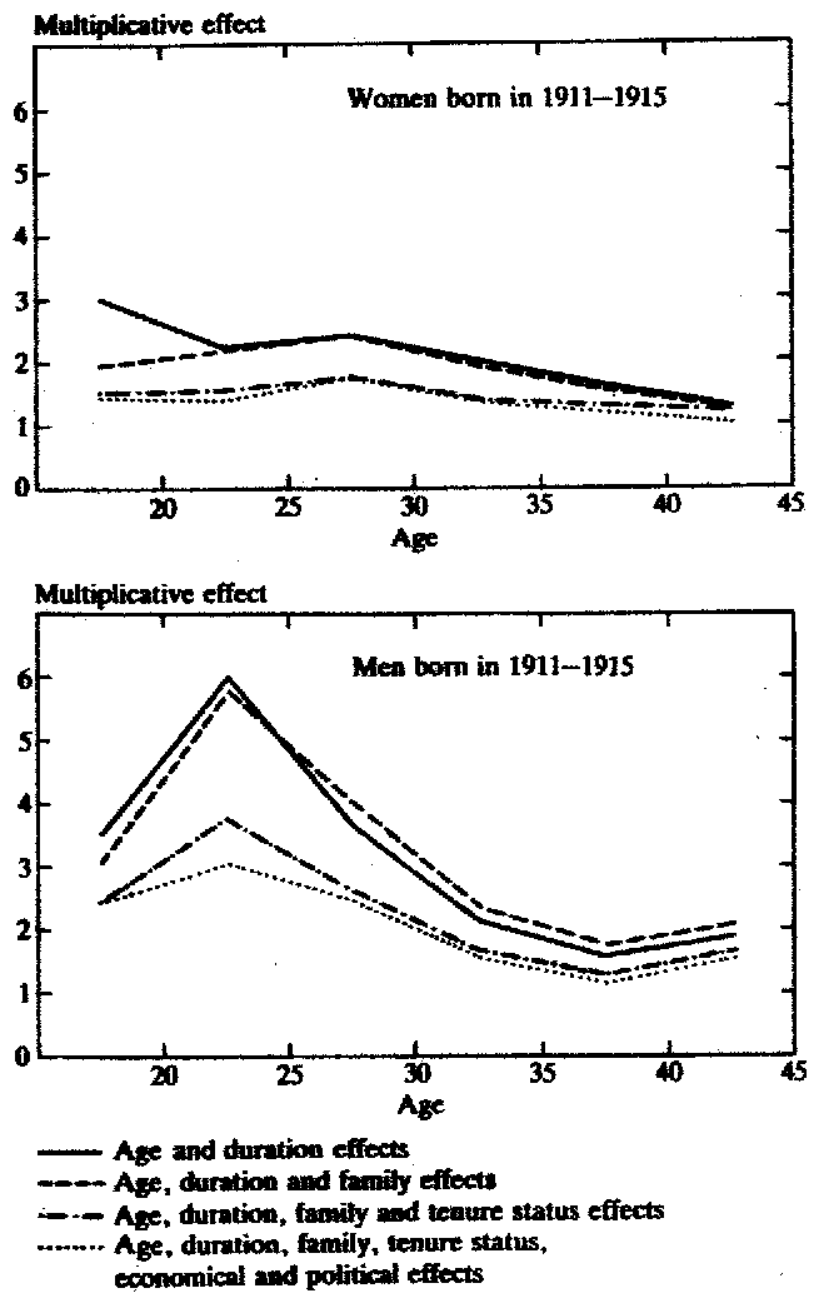

Figure 2 Multiplicative Effect on Moblity of Age According to the Sef of Considered Voriables: Cohort Born in 1911-1915

and 1915. Only the introduction of tenancy variables reduces the rates for all age-groups and for all cohorts. Later, the introduction of economic and political variables had only a small effect on $\because$ the mobility rates of older cohorts (i.e. only a limited diminution); but they had an important -. effect on the more recent cohorts, cancelling out any age effect. We can therefore observe that, though the introduction of the different variables greatly reduces the age effect for the older cohorts (for example, by reducing it by half for men in the 20-24 age group) the age effect always remains significant. Thus, we can say that, for those older cohorts, the age grading of family and economic life was less evident than for the more recent ones. In the latter case, the course of a life consists of more institutionally arranged life-stages over which the individual has only limited control (Mayer and Müller, 1982). In fact, for the last cohort, we are able to explain all age effects previously noted in the different stages of the individual's family, economic, and political life.

On the other hand, we can observe a reduction, in absolute terms, of the duration of residence effect. This suggests that what might be attributed to a tendency for mobility is partially due to heterogeneity in terms of family or occupational status. However when introducing the whole set of 

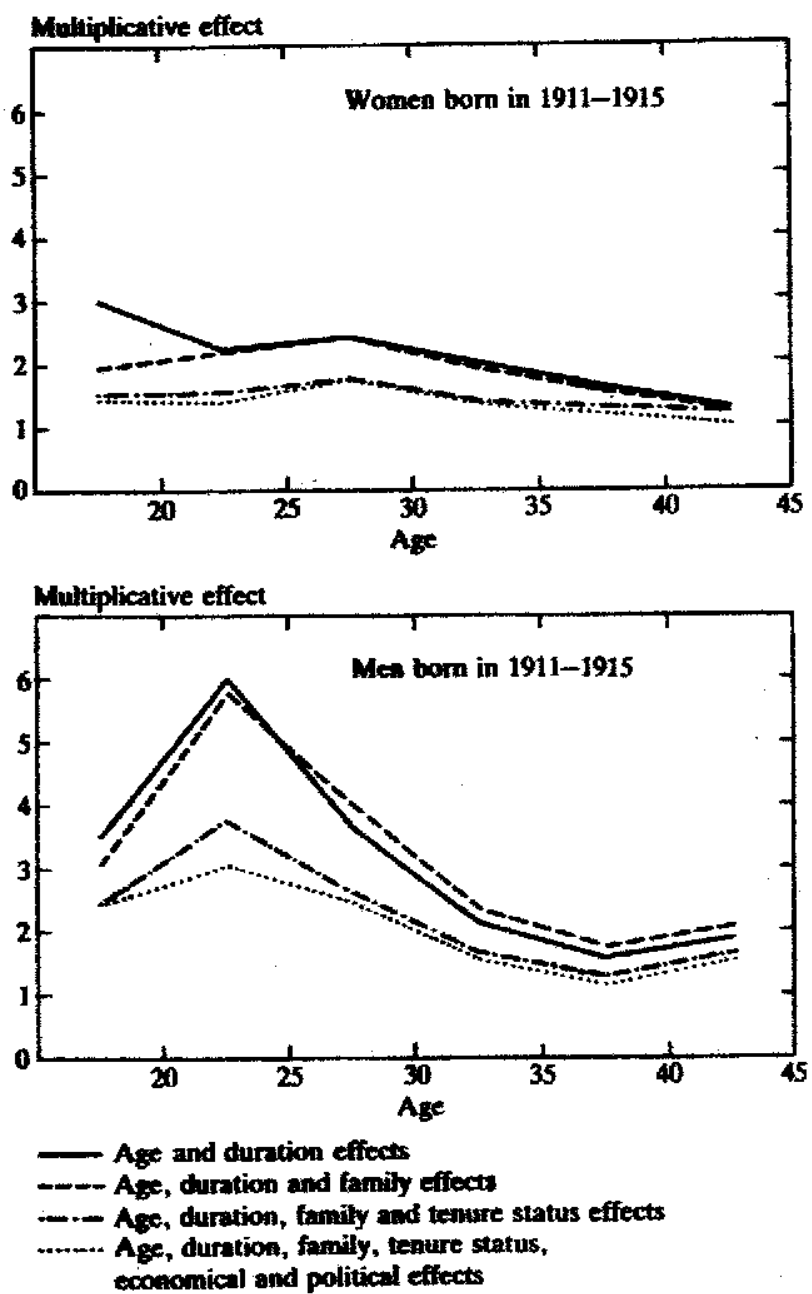

Fioure 2 Multiplicative Effect on Mobility of Age According to the Set of Considered Variables: Cohort Born in 1911-1915

and 19i5. Only the introduction of tenancy variables reduces the rates for all age-groups and for all cohorts. Later, the introduction of economic - and political variables had only a small effect on $\because$ the mobility rates of older cohorts (i.e. only a limited diminution); but they had an important $\therefore$ effect on the more recent cohorts, cancelling out any age effect. We can therefore observe that, though the introduction of the different variables greatly reduces the age effect for the older cohorts (for example, by reducing it by half for men in the 20-24 age group) the age effect always remains significant. Thus, we can say that, for those older cohorts, the age grading of family and economic life was less evident than for the more recent ones. In the latter case, the course of a life consists of more institutionally arranged life-stages over which the individual has only limited control (Mayer and Müller, 1982). In fact, for the last cohort, we are able to explain all age effects previously noted in the different stages of the individual's family, economic, and political life.

On the other hand, we can observe a reduction, in absolute terms, of the duration of residence effect. This suggests that what might be attributed to a tendency for mobility is partially due to heterogeneity in terms of family or occupational status. However when introducing the whole set of 
mobility follows the departure of children. We have also been able to pinpoint an 'inheritability' factor: the more mobile the parents have been during an individual's childhood, the more mobile be or she is likely to become. These conclusions tell us that the microeconomic cross-sectional approach usually used to study migration may be extended to include the family life-cycle.

To elucidate the more complex interferences between fertility and mobility, we have had to use more appropriate non-parametric methods. We have been able to disentangle the complex relationship which may exist, for example, between age and duration of residence. In particular, we

- have shown that women who marry at a younger age undertake migrations related to increases in - family size more frequently than women who marry at a later age.

Tenant status also plays a major part in the mobility process. As long as individuals live with their parents, their mobility rate will remain low. If they become tenants, their mobility increases. It increases further if they are accommodated by their employer. However, when they suceed in becoming the owner of a residence, their migration propensity will decrease to one seventh of the mobility of a tenant.

Only for the more recent cohorts does the level of educational or vocational training influence mobility. The higher the level of training, the higher the mobility rate. This result may be related to the fact that a larger geographical area is required to provide job opportunities for highly specialized individuals. Such an interpretation does not hold true for the older cohort, nor do the results suggest any other influence of training on mobility.

We find different mobility rates according to occupational status: the lowest rate for farmers, low rates for other agricultural workers, higher rates for those working in a managerial capacity.

- Again, mobility rates appear to be related to the spatial extension of the work involved.

$\because \quad$ Finally, military and war periods and periods of economic crisis also affect the mobility rate.

Another important result has been the elucidation of differences between cohorts born before and after 1926. In principle, the older cohorts began working before World War II, while the younger cohorts began working during or after the war. In many instances, their perception of space was changed as was that of French society as a whole. Now, a more age-graded society has emerged in which educational and vocational levels play an important part.

We may comment that space seems closely interrelated with the social bife-cycle. The spatial dimension is rarely taken into consideration in sociological studies of the life-cycle: nevertheless, it plays an important part. Since we have shown that space is not simply a consequence, but rather an interrelated aspect of the life-cycle, we hope that further studies will take greater account of space and spatial mobility.

The methodology used in this paper seems to hold great promise for future work. It has permitted us to disentangle highly complex interrelations and to provide rigorous tests of statistical significance. First, non-parametric methods may be generalized in order to take into account a more important variety of interactions. We have here presented a relationship between fertility and spatial mobility. In the future we will have to study different types of interactions as between, for example, marriage and occupational mobility, as well as interactions among several phenomena.

Secondly, the parametric analysis used in this paper takes into accotunt only the value of different co-variants at the beginning of each event interval. Marital status, house ownership, employment status, etc. can obviously change between moves. In future work, therefore, we should try to incorporate time-dependent infuential processes in the analysis. Some of these processes, like economic crises and periods of war, may be external to the individual under study. Others may be generated by the individual, as when a change in his relational system induces changes in his behaviour.

It will also be important to try to account for differences in types of moves. We have shown elsewhere (Courgeau, 1984) that family life-cycle infuences mainly local moves; it has relutively little effect on ones between départements. In future work, it will be necessary to take the nature of spatial moves into account.

Finally, the analysis of local dependence seems to be of major interest for future research, as it permits us to go beyond the concept of stochastic dependence on the introduction of an irreversible 
time component in the analysis. In other words, it will permit us to go beyond conventional concepts of simple correlation towards the identification of causal relations.

\section{APPENDIX 1: INVESTIGATIONS OF THE ASSOCIATION BETWEEN FERTILITY AND MIGRATION}

We present here a more general model from which the non-parametric model used in this paper can be taken. We work with a two-dimensional state space in which a state is specified as an ordered pair $(l, n)$, where $l$ is the number of moves previously undertaken and $n$ the number of children previously born.

Assume that all individuals start out in state $(0,0)$ at marriage and let $t$ denote the duration of his or her marriage. We will also consider time since the most recent move $(u)$ and the most recent childbirth (v). Then, in general, the migration intensity can be written as $E_{f}^{\prime n}(u, v)$ and the corresponding childbearing intensity as $\varphi_{l}^{h n}(u, v)$.

According to the hypothesis applied to the set of variables $(l, n, t, u, v)$, we will be able to provide evidence for different kinds of model.

A first set of hypotheses used in this paper assumes that both of the previous intensities are independent of $u$ and $v$, and the migration intensity depends only on the number of previous childbirths while the childbearing intensity depends only on the number of moves previously undertaken. These assumptions make the estimators $e$ and $f$ i reasonable if the intensities are constant in each marriage duration interval $i$.

Such a simplification will take into account the longer-term effects of the level of each of the two status dimensions we consider (childbearing parity and number of moves) on the other. However, it will also be important to take into account the short term after-effects of one event on the other. In this case, if the birth of a child modifies the migratory behaviour of his parents, then $\varepsilon_{t}^{m}(u, v)$ should depend on $v$, at least for a small $v$, and this effect should exist in addition to its possible dependence on $n$. We will have to estimate $e^{\eta}(v)$ to obtain this short-term after-effect of event occurrences. In the same way, if a new spatial move modifies the couple's reproductive behaviour, then $\varphi_{t}^{\prime n}(u, v)$ should depend on $u$, at least for a small $u$, in addition to its possible dependence on $L$.
We will have to estimate $f(u)$. However, the great increase in the number of estimators and the limited number of surveyed persons do not permit us to estimate such dependence here.

\section{APPENDIX 2: PARAMETRIC METHODS OF ANALYSIS}

We first need to give some general definitions before developing a parametric model. Let $T_{\text {? }}^{0}$ be a non-negative random variable representing the failure time of an individual. The probability distribution of $T_{i}^{0}$ can be specified in different ways.

Let us first define the probability of remaining in ?' the same state, from the date of entering into the state to a given time $t$, as dependent on a set of characteristics of the individual at the beginning of the observation $\left(X_{i}\right)$. This model is specific up to a parameter vector $\theta$ and we can write this probability as :

$$
S\left(t ; X_{i}, \theta\right)=P\left(T_{i}^{\theta} \geqslant t ; X_{b}, \theta\right)
$$

We can also define a probability density function for migration as:

$$
\begin{aligned}
m\left(t ; X_{i}, \theta\right)=\lim _{\Delta t \rightarrow 0} & \\
& \frac{P\left(t \leqslant T_{i}^{0}<t+\Delta t ; X_{b}, \theta\right)}{\Delta t} \\
& =-\frac{\delta S\left(t ; X_{b} \theta\right)}{8 t}
\end{aligned}
$$

Finally, we can define an instantaneous rate of failure by the following equation:

$$
\begin{aligned}
& \mu\left(t ; X_{i} \theta\right)=\lim _{\Delta t \rightarrow 0} \\
& \frac{P\left(t \leqslant T_{i}^{0}<t+\Delta t ; X_{i}, \theta \mid T_{i}^{0} \geqslant t\right)}{\Delta t} \\
& =-\frac{\delta S\left(t ; X_{b}, \theta\right)}{S\left(t ; X_{b}, \theta\right) \delta t}
\end{aligned}
$$


However, from retrospective surveys we have for some duration of residence $T_{i}$ a censored observation, so that $T_{i}<T_{i}^{0}$. We can introduce, for each individual, a censoring mechanism acting on the data. Specifically, we assume that the censoring time $C_{i}$ is a random variable with survivor and density functions $O_{i}(t)$ and $q_{i}(t)$. But as we consider that the censoring times are stochastically independent both of each other and of the failure time, we can write, introducing a dummy variable $\delta_{i}$, that is zero if the $i^{\text {th }}$ item is censored, one in the other case:

$$
\begin{aligned}
\therefore P\left(t \leqslant T_{i}<t+\Delta t ; \delta_{i}=1,\right. & \left.X_{i}, \theta\right) \\
& =O_{i}(t) m\left(t ; X_{i}, \theta\right) \Delta t \\
\therefore P\left(t \leqslant T_{i}<t+\Delta t ; \delta_{i}=0, X_{i}, \theta\right) & \\
& =q_{i}(t) S\left(t ; X_{i}, \theta\right) \Delta t
\end{aligned}
$$

As neither $O_{i}$ nor $q_{i}$ are informative about $\theta$, the likelihood of the data is:

$$
L(\theta) a \prod_{i=1}^{n} m\left(t_{i} ; X_{i}, \theta\right)^{\delta_{i}} \quad S\left(t_{b} X_{b} \theta\right)^{1-\delta_{i}}
$$

when $n$ is the number of observed durations of residence. It is then possible to estimate the parameter vector $\theta$ with a maximum likelihood method, using a given form for the instantaneous rate. In this paper, we use a generalized Gompertz model.

$$
\mu\left(t, X_{i}, \theta\right)=\exp \left(\theta X_{i}+\theta_{0} t\right)
$$

which introduces a dependence between the instantaneous rate and the duration of residence. An iterative procedure has been used here, that is a - variant of the classical Newtonian method, to find

- an estimate of $\theta$ and a variance-covariance matrix 1. of the $\theta$ coefficients 8 .

\section{NOTES}

I. This rate was estimated only for the two surveys taken together.

2. For this survey, right censoring occurs as the case where individuals enter the study at random over time and the analysis is carried out the time of the survey.

3. When the usual hypothesis is that those who have a child during the $f^{\text {th }}$ year of marriage are exposed to the risk of migrating upder parity $n$ only for half the year on average $N_{i}^{f}-N_{1}^{h+1}$ in the denomingtor of this rate should be

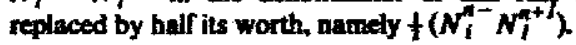

4. To assure comparable results, we consider here only thow periods beginning before the individual was 45 years old.

5. For example, five years after marriage, the test presented in Appendix 1 gives a cumulative value of 2-96, for the first cohort, which leads to the rejection of equality of rutes for women without children and women with one child, at a bevel of significance above 0.15 per cent.

6. Introducing those effects with a binary variable for each scale involves too many variables.

7. We are indebted to Jan Hoem whose comments helped enormously to clarify such a model.

8. We used a Fortran computer program called RATE written by $N$. Tuma and D. Paste. This proprem can extimate four types of models when event-hictory data are supplied. Some models also alfow the chringe process to vary over time or to depend on unobverved variables, is well as on observed variables (Tuma el al., 1979).

\section{ACKNOWLEDGEMENTS}

The author is indebted to Jan Hoem, Nico Keilman, Keri Ulich Mayer and Agge Sorensen for their valuable comments and discussions on a pretiminary version of this paper.

Thanks also go to Gitenn Carroll, Gordon Neil, David Pagel and Judy Salamon for proof-reading the English.

\section{REFERENCES}

Aaten O, Borgan 0, Keiding N, Thorman J. (1980): Interaction between life history events: Nonparametric annlysis for prospective and retrospective date in the presence of censoring', Scandinavian Joumal of Statistics 7: $161-171$.

Bishop Y, Fienberg S, Holland P. (1978): Discrete Multivariate Analysis: Theory and Practice, Cumbridge, London: The MIT Press.

Calot, G, Henry L. (1972): 'Nuptialtité et fecondité des mariages en France d'apres l'enquete de 1962', Population, 27: $191-208$.

Coleman J. (1981): Longitudinal Data Analysis, New York: Basic Books.

Courgeau D. (1977): 'Interférences entre phésomènes demographiques', Population, 32, numieno special; 81-93. (1979): 'Migration and demographic phenomenn in France' in White J. (ed), The Urben Impact of Internal Migration. Chapel Hill: University of North Cerclina Press.

(1980): Analyse quantitative des migrations humaines, Paris: Masson.

(1984): 'Relations entre cycle de vie et migrations', Population, 39: 483-514.

(1984): "Analysis of the French Mieration, Famity and Occupation History Survey', Materialien zur Bewälkerungswissenschioft, 38: 85-102.

(1984): 'Effet de dectarations errondes sur une andyese de donné migratoires', Chaire Queteler; Migrations internes, forthcoming. 
Courgeau D, Lefebrre M. (1982): 'Les migrations internes en France de 1954 1975. II. Migrations et urbanisation', Population, 37: 34!-370.

Deville J-C. (1977): 'Analyse harmonique du calendrier de constitution des familles en France. Disparites sociales et évolution de 1920 a $1960^{\circ}$, Population, 32: 17-63.

(1979): 'Près dun Francais sur dix a changè de régjos', Economie et Statistique, 107: 5-16.

Duchène J. (1984): 'Un test de fiabilite des enqueies rétrospectives "Biographie familiale, professionnelle at migratoire", Choire Quetelet: Migrations internes, forthcoming.

Eidridge H. (1964): "A Cohort Approach to the Amalysis of Migration Differemtials', Demography, 31: 212-219.

Ginsberg R. (1979): 'Timing and Duration Effects in Residence Histories and other Longitudinal Data. II. Studies of duration effects in Norway, 1965-1971, Regional Science and Urban Economics, 9, 369-392.

Hoem J. (1976); 'Fertility and Out-migration. Reflexions on Research Approaches in Empirical Investigation of the Association between Two Demographic Phenomena' in Anderson A, Holmberg 1. (eds), Demographic Economic and Social Interactions, Cambridge, Mass: Batinger Publ. Co.

(1983): 'Weighting, Misclassification and other issues in the Analysis of Survey Samples of Life Histories'. Stockholm Reports in Demography, 11.

Hoem J, Jensen V. (1982): 'Multistate Life Table Methodology. A probabilistic critique' in Land K, Rogers A. (eds.), Multidimensional Mathematical Demography, New York: Academic Press.

Kalbfieisch J, Prentice R. (1980): The Statistical Analysis of Failure Time Data, New York: Wiley.

Kimball S. (1954): 'The Nature of Human Groups', The Talladega Story, University of Alabama Press, 13-32.

Long L. (1970): 'The Fertility of Migrants to and within North America', Mibank Memorial Fund Quarterly, 3: 297-316.
(1973): 'Migration Differentials by Education and Occupation: Trends and Variations", Demography, 10: 243-258.

Mayer K U, Miller W. (1982): 'The State and the Structure of the Life Course', in Sorensen, Weinert, Sherrod (eds.), Human Development, forthcoming.

Morrison P. (1983): 'Introduction and overview' in Morrison P. (ed.), Population Monements: their Forms and Functions in Urbanization and Development, Liege: Ordina Editions.

Pitrou A, Battagliola F, Buisson M, Rousier N, Ruffier J, Toussaint Y. (1983): Trajectoires professionnelles et stratégies familiales, Paris: CNRS.

Riandey B. (1984): "Lenquête "Biographie familiale, professionnelle at migratoire"', Chaire Quetelet: Migrations internes, forthooming.

Rogers A, Requillet R, Castro L. (1978): 'Model Migration Schedules and their Applications", Environment ana' , Planning, 10, special issue: 475-502.

Sandefur G, Scott W. (1981): 'A dynamic analysis of migration: an assessment of the effects of age, family and, career variables', Demography, 18: 355-368.

Tuma N. Hannan M. (1984): Social Dynamies: Models and Methods, New York: Academic Press.

Tuma N, Hannan M, Groeneveld L. (1979): 'Dynamic Analysis of Event Histories', American Journal of Soclology, 84: 820-854.

Zelinsky W. (1983): "The Impasse in Migration Theory: a Sketch Map for Potential Escapees' in Morrison P. (ed), Population Movements: their Forms and Functions in Urbanization and Development, Liège: Ordina Editions. 